\title{
CRESCIMENTO IN VITRO DE ORQUÍDEA EM DIFERENTES CONCENTRAÇÕES DE URÉIA EM SUBSTITUIÇÃO AO NITRATO DE AMÔNIO
}

\author{
FERREIRA, Jéferson Pereira ${ }^{1}$ \\ MARTINS, João Paulo Rodrigues ${ }^{1}$ \\ PALAORO, Geferson Junior ${ }^{2}$ \\ FIGUEIREDO, Deleon Demoner Caulyt ${ }^{2}$ \\ SCHMILDT, Edilson Romais ${ }^{3}$ \\ SCHMILDT, Omar ${ }^{3}$
}

Recebido em: 2012-01-25

Aprovado em: 2012-03-08

ISSUE DOI: $10.3738 / 1982.2278 .693$

\begin{abstract}
RESUMO: As orquídeas são frequentemente propagadas por meio das técnicas de cultura de tecidos, porém o elevado custo do nitrato de amônio empregado no meio de cultivo tem levado a busca de fontes alternativas de nitrogênio. Objetivou-se estudar a viabilidade técnica da substituição do nitrato de amônio por uréia, como fonte de nitrogênio no meio de cultivo, para a propagação de Cattleya bowringiana. Plântulas de Cattleya bowringiana previamente estabelecidas in vitro, com comprimento entre 0,5 e $0,8 \mathrm{~cm}$, foram inoculados em meio de cultura $1 / 2$ MS, tendo a substituição do nitrato de amônio nas proporções $0,25,50,75$ e 100\% por uréia sem alterar o balanço de nitrogênio fornecido pelo meio 1/2MS. O delineamento experimental foi inteiramente casualizado e as médias obtidas foram submetidas ao teste de Dunnett. A substituição total de sulfato de amônio por uréia não afetou o número, o comprimento e a massa fresca de brotos. No entanto, a substituição acima de $25 \%$ afetou o número e comprimento de raízes. A substituição parcial com $25 \%$ de uréia pode ser empregada na propagação in vitro de Cattleya bowringiana.
\end{abstract}

Palavras chave: Cattleya bowringiana O’Brien. Meio de cultura. Nitrogênio.

\section{GROWTH IN VITRO OF ORCHID IN DIFFERENT CONCENTRATIONS OF UREA IN AMMONIUM NITRATE REPLACEMENT}

SUMMARY: Orchids are often propagated through tissue culture techniques, but the high cost of ammonium nitrate used in the culture medium has led the search for alternative sources of nitrogen. The objective was to study the technical feasibility of replacing the ammonium nitrate by urea as a nitrogen source in the culture medium for the propagation of Cattleya bowringiana. Seedlings of Cattleya bowringiana previously established in vitro, with length between 0,5 and $0,8 \mathrm{~cm}$ were inoculated in $1 / 2$ MS medium, with the substitution of ammonium nitrate in the proportions $0,25,50,75$ and $100 \%$ for urea without changing nitrogen balance provided by the $1 / 2$ MS medium. The experimental design was completely randomized and the averages were subjected to Dunnett test. Total replacement of ammonium sulfate by urea did not affect the number, length and fresh weight of shoots. However, above $25 \%$ replacement affecting the number and length of roots. The partial substitution with $25 \%$ urea can be used in vitro propagation of Cattleya bowringiana.

Keywords: Cattleya bowringiana O’Brien. Growing medium. Nitrogen.

\section{INTRODUÇÃO}

O gênero Cattleya (Orchidaceae), de ocorrência natural no Brasil, é bastante popular e atinge altos preços no mercado interno e externo, procurado por colecionadores, orquidófilos, decoradores de ambiente e apreciadores (SOARES et al., 2011).

\footnotetext{
${ }^{1}$ Mestrando em Agricultura Tropical no Centro Universitário Norte do Espírito Santo (CEUNES/UFES), Rodovia BR 101 Norte, km 60, Bairro Litorâneo, 29932-540, São Mateus/ES. E-mail: Jeferson.p.ferreira@ hotmail.com; jprmartins@ yahoo.com.br

${ }^{2}$ Engenheiro Agrônomo. Centro Universitário Norte do Espírito Santo (CEUNES/UFES), Rodovia BR 101 Norte, km 60, Bairro Litorâneo, 29932-540, São Mateus/ES. E-mail: palaorojp@hotmail.com; deleondf@ hotmail.com

${ }^{3}$ Professor Doutor no Centro Universitário Norte do Espírito Santo CEUNES/UFES), Rodovia BR 101 Norte, km 60, Bairro Litorâneo, 29932-540, São Mateus/ES. E-mail: edilson@npd.ufes.br; omar-schmildt@ig.com.br
} 
As técnicas de cultura de tecidos são frequentemente relatadas como alternativa viável para produção em larga escala de orquídeas com qualidade comprovada, sendo a composição mineral do meio de cultivo um dos fatores mais importantes e já estudados por Sorace et al. (2008), Araújo et al. (2009), Pasqual et al. (2009) e Cardoso e Ono (2011).

A fonte de sais minerais fornecida aos explantes de orquídeas durante o cultivo in vitro é extremamente importante, assim como sua concentração (ARAÚJO et al., 2009). O nitrogênio é um dos principais nutrientes essenciais, podendo ser absorvido, principalmente, na forma de nitrato e amônio. Por ser constituinte de várias biomoléculas essenciais, sua assimilação se dá em diversos processos metabólicos da planta (SAKUTA et al., 1987).

O nitrato de amônio, normalmente empregado nos meios de cultivo, possui elevado custo e dificuldade de aquisição, o que tem levado à realização de trabalhos com o objetivo de buscar uma alternativa para a substituição dessa fonte de nitrogênio (FRÁGUAS et al. 2003).

A uréia pode ser utilizada no meio de cultura como fonte adicional de nitrogênio, e já foi testada no cultivo in vitro de eucalipto (GROTHGE, 1992), bromélias (ENDRES; MERCIER, 2001), gloxínias (FRÁGUAS et al., 2003), bananeira (RAMOS et al., 2009) e, amoreira-preta (VILLA et al., 2009). Esse composto orgânico possui menor custo em relação ao nitrato de amônio, podendo ser utilizado como uma fonte viável de $\mathrm{N}$ para a substituição parcial ou total no meio de cultivo (MOREIRA et al., 2007).

Assim, objetivou-se estudar a viabilidade da substituição total ou parcial do nitrato de amônio por uréia como fonte de nitrogênio no meio de cultura in vitro da orquídea Cattleya bowringiana.

\section{MATERIAL E MÉTODOS}

O experimento foi conduzido no laboratório de Biotecnologia Vegetal do Centro Universitário Norte do Espírito Santo da Universidade Federal do Espírito Santo, localizada no município de São Mateus.

Flores de Cattleya bowringiana O'Brien (Orchidaceae) foram polinizadas artificialmente em casa de vegetação e as cápsulas foram colhidas após seis meses. Essas foram desinfestadas com álcool 70\% por 1 minuto e solução de hipoclorito de sódio $(2,5 \% \mathrm{~m} / \mathrm{v}$ de cloro ativo) por 15 minutos. Posteriormente, foram lavadas com água destilada autoclavada para remoção do excesso da solução desinfestante. As sementes foram extraídas com auxílio de pinça e semeadas em potes de $250 \mathrm{~mL}$ contendo $35 \mathrm{ml}$ de meio de cultivo MS (MURASHIGE; SKOOG, 1962) meia força (1/2 MS), o qual fornece $825 \mathrm{mg} \mathrm{L}^{-1}$ de nitrato de amônio e suplementado com 30 g.L $\mathrm{L}^{-1}$ de sacarose e solidificado com 7,0 g.L $\mathrm{L}^{-1}$ de ágar. $\mathrm{O}$ pH do meio de cultivo foi ajustado em 5,7 antes da autoclavagem a $120^{\circ} \mathrm{C}$, durante 20 minutos. Em sala de cultivo, os explantes foram mantidos por 180 dias sob lâmpadas fluorescentes fornecendo $25,2 \mu \mathrm{mol} \mathrm{m} \mathrm{m}^{-1}$ de fluxos de fótons fotossintéticos, 16 horas de fotoperíodo e temperatura de $27 \pm 2{ }^{\circ} \mathrm{C}$.

As plântulas obtidas após seis meses e com comprimento entre 0,5 e $0,8 \mathrm{~cm}$ foram inoculadas em potes de $250 \mathrm{~mL}$ contendo $35 \mathrm{~mL}$ de meio de cultura semelhante ao da fase de semeadura, com exceção da concentração de nitrato de amônio. Os tratamentos consistiram da substituição gradual $(0,25,50,75$ e $100 \%)$ do nitrato de amônio $\left(\mathrm{NH}_{4} \mathrm{NO}_{3}\right)$ por uréia $\left(\mathrm{CH}_{4} \mathrm{~N}_{2} \mathrm{O}\right)$ não sendo alterado o balanço de nitrogênio fornecido pelo meio MS. O delineamento experimental foi inteiramente casualizado com cinco repetições, sendo cada parcela composta por cinco plântulas. As condições físicas da sala de cultivo foram as mesmas fornecidas na fase de semeadura.

A avaliação foi realizada após 120 dias de cultivo e as variáveis analisadas foram: número de brotos por plântula, comprimento dos brotos, número de raízes, comprimento da maior raiz de cada broto e massa de matéria fresca das plântulas. 
Os dados obtidos foram submetidos à análise de variância e as médias comparadas pelo teste de Dunnett (ZIMMERMANN, 2004), sendo a testemunha o meio com 100\% de nitrato de amônio. As análises foram feitas com auxílio do programa Genes (CRUZ, 2006).

\section{RESULTADOS E DISCUSSÃO}

A Tabela 1 apresenta resultados da análise de variância onde se verifica que houve diferença estatisticamente significativa para número de raízes (NR) e para comprimento da maior raiz (CMR).

TABELA 1 - Resumo da análise de variância do desenvolvimento in vitro de orquídea Cattleya bowringiana em função da presença ou não de uréia em substituição ao nitrato de amônio (NA) em meio $1 / 2 \mathrm{MS}$

\begin{tabular}{|c|c|c|c|c|c|c|}
\hline \multirow{2}{*}{$\begin{array}{l}\text { Fontes de } \\
\text { Variação }\end{array}$} & \multirow{2}{*}{ GL } & \multicolumn{5}{|c|}{ Quadrado médio } \\
\hline & & NB & CB & NR & CMR & MF \\
\hline (Tratamento) & (4) & $0,1569^{\mathrm{ns}}$ & $0,0874^{\mathrm{ns}}$ & 1,1813 ** & $2,4886^{* *}$ & $342,832^{\mathrm{ns}}$ \\
\hline Uréia & 3 & $0,1268^{\mathrm{ns}}$ & $0,1140^{\mathrm{ns}}$ & $1,4004 * *$ & $1,4962 *$ & $125,470^{\mathrm{ns}}$ \\
\hline Uréia x NA & 1 & $0,2472^{\mathrm{ns}}$ & $0,0075^{\mathrm{ns}}$ & $0,5238 *$ & $5,4658 * *$ & $994,917^{\mathrm{ns}}$ \\
\hline Residuo & 17 & 0,1072 & 0.1319 & 0,0906 & 0,4300 & 382,5289 \\
\hline CV (\%) & & 29,64 & 34,07 & 26,99 & 47,48 & 26,43 \\
\hline
\end{tabular}

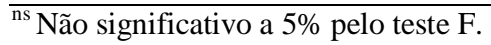

*, ** Significativo a 5 e $1 \%$, respectivamente pelo teste $\mathrm{F}$.

$\mathrm{NB}=$ número médio de brotos; $\mathrm{CB}=$ comprimento médio das brotações $(\mathrm{cm})$; $\mathrm{NR}=$ número de raízes; $\mathrm{CMR}=$ comprimento da maior raiz $(\mathrm{cm}) ; \mathrm{MF}=$ massa fresca total por plântula $(\mathrm{mg})$.

Pelo teste de Dunnett, o número médio de raízes e o comprimento médio da maior raiz no tratamento controle ( $100 \%$ de nitrato de amônio) foram semelhantes ao verificado quando houve $25 \%$ de substituição da fonte nitrogenada convencional por uréia $\left(206,25 \mathrm{mg} \mathrm{L}^{-1}\right)$, e as demais dosagens apresentaram valores médios inferiores ao controle (Tabela 2).

TABELA 2 - Médias de cinco características em orquídea Cattleya bowringiana submetidas a crescimento in vitro em função da presença ou não de uréia em substituição ao nitrato de amônio (NA) em meio $1 / 2 \mathrm{MS}$

\begin{tabular}{cccccccc}
\hline \multicolumn{2}{c}{ Tratamento $(\%)$} & & \multicolumn{5}{c}{ Médias } \\
\cline { 1 - 5 } \cline { 5 - 7 } NA & Uréia & & NB & CB & NR & CMR & MF \\
\hline 100 & 0 & & $1,30 \mathrm{a}$ & $1,10 \mathrm{a}$ & $1,40 \mathrm{a}$ & $2,30 \mathrm{a}$ & $86,40 \mathrm{a}$ \\
75 & 25 & & $1,20 \mathrm{a}$ & $1,20 \mathrm{a}$ & $1,80 \mathrm{a}$ & $1,90 \mathrm{a}$ & $76,00 \mathrm{a}$ \\
50 & 50 & & $1,15 \mathrm{a}$ & $1,12 \mathrm{a}$ & 0,76 & 0,87 & $71,36 \mathrm{a}$ \\
25 & 75 & & $0,96 \mathrm{a}$ & $1,01 \mathrm{a}$ & 0,69 & 0,77 & $68,00 \mathrm{a}$ \\
0 & 100 & & $0,80 \mathrm{a}$ & $0,82 \mathrm{a}$ & 0,67 & 0,66 & $62,40 \mathrm{a}$ \\
\hline \multicolumn{2}{c}{ DMS } & & 1,12 & 0,61 & 0,60 & 1,11 & 33,27 \\
\hline
\end{tabular}

Médias dos tratamentos com presença de uréia seguidas da letra a, em cada coluna, não diferem da testemunha (100\% NA e $0 \%$ Uréia) a $5 \%$ de probabilidade pelo teste de Dunnett.

$\mathrm{NB}=$ número médio de brotos; $\mathrm{CB}=$ comprimento médio das brotações $(\mathrm{cm})$; $\mathrm{NR}=$ número de raízes; $\mathrm{CMR}=$ comprimento da maior raiz $(\mathrm{cm}) ; \mathrm{MF}=$ massa fresca total por plântula $(\mathrm{mg})$.

As doses de uréia empregadas no meio de cultivo variam em função do genótipo (ENDRES; MERCIER, 2001; RAMOS et al., 2009) e podem levar a efeitos fitotóxicos nos explantes de plantas ornamentais com tecidos mais tenros, principalmente quando cultivadas in vitro. Essas podem apresentar menor desenvolvimento do sistema radicular (FRÁGUAS et al., 2003; MOREIRA et al., 2007), o que condiz com o verificado em C. bowringiana. 
As variáveis número de brotos, comprimento dos brotos e massa fresca foram estatisticamente semelhantes ao controle. A semelhança estatística dos valores médios pode ser explicada devido ao tempo de avaliação, pois a espécie $C$. bowringiana possui crescimento lento. Isto é comum em espécies da família Orchidaceae comparativamente às outras famílias de plantas herbáceas. SOUTO et al., (2010), trabalhando com o cultivo in vitro da orquídea Cattleya bicolor, verificaram que diferenças morfométricas entre tratamentos foram verificadas aos 360 dias e não haviam sido verificadas aos 180 dias de cultivo.

Moreira et al. (2007) e Villa et al. (2009) observaram decréscimo do comprimento da parte aérea de abacaxizeiro cv. Pérola (Ananas comosus) e amoreira-preta (Rubus sp), respectivamente, com o aumento da concentração de uréia em substituição ao nitrato de amônio.

A micropropagação de alguns clones de eucalipto (GROTHGE, 1992) e algumas variedades de banana (RAMOS et al., 2009) se mostraram prejudicadas por doses de uréia acima de $200 \mathrm{mg} \mathrm{L}^{-1}$, de forma semelhante ao verificado neste trabalho para C. bowringiana.

Nos meios com altas concentrações de uréia observou-se descoloração parcial das folhas e morte de algumas plântulas. Segundo Torres-Netto et al. (2002), o aspecto visual da parte aérea pode dar uma boa indicação da qualidade. A coloração verde indica uma ótima disponibilidade de $\mathrm{N}$ no tecido foliar, bem como excelente quantidade de pigmentos fotossintéticos, o que é um ótimo fator para a micropropagação.

\section{CONCLUSÃO}

Recomenda-se o uso de uréia em até no máximo $200 \mathrm{mg} \mathrm{L}^{-1} \mathrm{em}$ substituição ao nitrato de amônia em meio de cultivo $1 / 2$ MS na micropropagação de Cattleya bowringiana.

\section{REFERÊNCIAS}

ARAÚJO, A.G. et al. Fontes de nitrogênio no crescimento in vitro de plântulas de Cattleya loddigesii Lindl. (Orchidaceae). Acta Scientiarum: Biological Sciences, Maringá, v.31, n.1, p.35-39, 2009.

CARDOSO, J.C.; ONO, E.O. In vitro growth of Brassocattleya orchid hybrid in different concentrations of $\mathrm{KNO}_{3}, \mathrm{NH}_{4} \mathrm{NO}_{3}$ and benzylaminopurine. Horticultura Brasileira, Brasília, v.29, n.3, p.359-363, 2011.

CRUZ, C. D. Programa Genes: estatística experimental e matrizes, Viçosa: Editora UFV, 2006, 285 p.

ENDRES, L.; MERCIER, H. Ammonium and urea as nitrogen sources forbromeliads. Journal of Plant Physiology, Stuttgart, v.158, p.205-212, 2001.

FRÁGUAS, C.B. et al. Micropropagação de gloxínia em diferentes concentrações de nitrato de amônio e uréia. Ciência \& Agrotecnologia, Lavras. V.27, n.4, p.811-815, jul./ago., 2003.

GROTHGE, M. T. Efeito de várias fontes de nitrogênio na multiplicação in vitro de clones de Eucalyptus grandis HILL ex MAIDEN. 1992. Dissertação (Mestrado) - Escola Superior de Agricultura Luiz de Queiroz, Piracicaba, 1992.

MOREIRA, M.A.et al. Uréia como fonte alternativa de nitrogênio na micropropagação de abacaxizeiro cv. Pérola. Acta Scientiarum: Agronomy, Maringá, v.29, supl., p.689-693, 2007. 
MURASHIGE, T.; SKOOG, F. A revised medium for rapid growth and bioassays with tobaco tissue cultures. Physiologia Plantarum, Copenhagen, v. 15, n. 3, p. 473-497. 1962.

PASQUAL, M. et al. Fontes de nitrogênio, polpa de banana e ágar no desenvolvimento in vitro de plântulas de orquídea. Horticultura Brasileira, Brasília, v.27, p.211-216, 2009.

RAMOS, R.S.et al. efeito da uréia no alongamento e enraizamento de microplantas de bananeira in vitro. Ciência \& Agrotecnologia, Lavras, v.33, Edição Especial, p.1842 -1846, 2009.

SAKUTA, M.; TAKAGI, T.; KOMAMINE, A. Effects of sucrose source on betacyanin accumulation and growth in suspension cultures of Phytolacea americana. Physiologia Plantarum, New York, v.71, n.4, p.459-463, 1987.

SOARES, J.D.R.et al. Fontes de silício na micropropagação de orquídea do grupo Cattleya. Acta Scientiarum: Agronomy, Maringá, v.33, n.3, p.503-507, 2011.

SORACE, M.et al. Crescimento in vitro de Oncidium baueri (Orchidaceae) em diferentes concentrações de macronutrientes e sacarose. Semina: Ciências Agrárias, Londrina, v.29, n.4, p.775-782, 2008.

SOUTO, J.S.et al. Efeitos do ácido naftalenoacético no desenvolvimento in vitro de Cattleya bicolor Lindl. (Orchidaceae). Revista Brasileira de Biociências, Porto Alegre, v.8, n.2, p.179-185, 2010.

TORRES NETTO, A.et al. Portable chlorophyll meter for the quantification of photosynthetic pigments, nitrogen and the possible use for assessment of the photochemical process in Carica papaya L. Brazilian Journal Plant Physiology, Campinas, v.14, p.203-210, 2002.

VILLA, F.et al. Utilização de nitrato de amônio e de uréia como fontes de nitrogênio na micropropagação de amoreira-preta. Scientia Agraria, Curitiba, v.10, n.5, p.365-370, 2009.

ZIMMERMANN, F. J. P. Estatística aplicada à pesquisa agrícola. Santo Antônio de Goiás: Embrapa Arroz e feijão, 2004. 400 p. 
